\title{
THE ROLE OF PHOSPHORUS AND SULFUR IN INCONEL 718 *
}

\author{
Xishan Xie, Xingbo Liu, Yaohe Hu, Bin Tang, Zhichao Xu, Jianxin Dong and Kequan Ni \\ University of Science \& Technology Beijing,, Beijing 100083, China \\ Yaoxiao Zhu \\ Institute of Metal Research, Academy of Sciences, Shenyang 110015, China \\ Shusen Tien \\ Fushun Steel Plant, Fushun 113001, China \\ Laiping Zhang \\ No.3 Steel Works of Changcheng Special Steel Co., Sichuan 621704, China \\ Wei Xie \\ Shanghai No. 5 Steel Works, Shanghai 200940, China
}

\begin{abstract}
Phosphorus and sulfur are generally regarded as the most common impurities and detrimental elements in nickelbase superalloys. For further understanding the role of $\mathrm{P}$ and $S$ in Inconel 718 nine experimental heats were melted on the base of conventional Inconel 718 chemical composition with variation of $\mathbf{P}$ (from 10 to $130 \mathrm{ppm}$ ) and $S$ (from 15 to $175 \mathrm{ppm}$ ) respectively. Phosphorus and sulfur both have almost no influence on strengths and ductilities at room temperature tensile test. Phosphorus also has no effect on the yield and ultimate strengths and clongation at $650^{\circ} \mathrm{C}$ tensile test. However, sulfur has an obviously decreasing effect on $650^{\circ} \mathrm{C}$ tensile elongation but no effect on yield and ultimate strengths.
\end{abstract}

Sulfur has a remarkable detrimental effect on stress rupture life and especially on ductility loss at $650^{\circ} \mathrm{C}$. However, phosphorus is in total difference to sulfur effect, generally can increase stress rupture life and ductility both.

Microstructure observation on grain structure, $\delta$-phase and strengthening phase $\gamma^{\prime \prime}$ and $\gamma^{\prime}$ can not reveal the effect of $P$ and $S$ on the morphology and amount of precipitates. Fractography analyses show different patterns of stress rupture specimens with the variation of $P$ and $S$ contents. Experimental results lead us to consider the segregation behaviors of $\mathrm{P}$ and $\mathrm{S}$ at grain boundaries, however the effect of $\mathrm{P}$ and $\mathrm{S}$ should be different.

* This project is supported by the Chinese National Natural Science Foundation and the Ministry of Metallurgical Industry.

\section{Superalloys 1996}

Edited by R. D. Kissinger, D. J. Deye, D. L. Anton

A. D. Cetel, M. V. Nathal, T. M. Pollock, and D. A. Woodford

The Minerals, Metals \& Materials Society, 1996
Background and Industrial Tests

The clean superalloy production is regarded to meet the strict demand of aero-engine and gas-turbine industries and cleanliness has been basically considered in two categories, i.e. inclusions and detrimental elements control $^{(1)}$. Phosphorus and sulfur are generally regarded as the most common inpurities and detrimental elements in $\mathrm{Ni}$-base superalloys. From the points of view on melting process improvement at industrial alloy production background and on basic understanding the role of $\mathrm{P}$ and $\mathrm{S}$ in Ni-base superalloys the present investigation was conducted in industrial and laboratorial scales.

Niobium segregation and Laves phase formation during solidification from molten metal has been regarded as the most serious problem in Inconel 718 production. Results of segregation study during solidification by means of metalography and electron-probe analyses show that $P$ and $S$ most seriously aggravate dentritic segregation by decreasing solidus temperature and lowering the maxium content of $\mathrm{Nb}$ in $\gamma$ solid solution and also moving the eutectic point $(\gamma+$ Laves $)$ to the higher content of $\mathrm{Nb}$ in the pseudo-binary phase diagram ${ }^{(2)}$. In result of these effects $P$ and $S$ (especially $P$ ) will favour the formation of isolated large-size blocky Laves phase instead of eutectic Laves ${ }^{(2,3)}$. Based on above mentioned experimental results the low segregation Inconel 718 with very low content of $\mathrm{P}$ ( $P<10 \mathrm{ppm}$ ) VIM+VAR industrial ingots (with diameters 406 or $423 \mathrm{~mm}$ ) were melted in Chinese steel works ${ }^{(2,4)}$.

The comparison of solidified structure sliced directly from the industrial production ingots (low segregation and conventional) shows the advantage of lower segegation and less amount of blocky Laves phase especially at the mid-radius and the center of low segregation Inconel 718 
Table I. Example of the Mechanical Properties Comparison between Low Segregation and Conventional Inconel 718 Die-Forging Disks.

\begin{tabular}{|c|c|c|c|c|c|c|c|c|c|c|}
\hline \multirow{2}{*}{ Alloy } & \multicolumn{4}{|c|}{$20^{\circ} \mathrm{C}$} & \multicolumn{4}{|c|}{$650^{\circ} \mathrm{C}$} & \multicolumn{2}{|c|}{$650^{\circ} \mathrm{C}, \quad 686 \mathrm{MPa}$} \\
\hline & $\begin{array}{c}\text { YS } \\
(\mathrm{MPa})\end{array}$ & $\begin{array}{c}\text { UTS } \\
\text { (MPa) }\end{array}$ & $\begin{array}{l}\text { EL } \\
(\%) \\
\end{array}$ & $\begin{array}{l}\text { RA } \\
(\%) \\
\end{array}$ & $\begin{array}{c}\mathrm{YS} \\
(\mathrm{MPa}) \\
\end{array}$ & $\begin{array}{r}\text { UTS } \\
\text { (MPa) } \\
\end{array}$ & $\begin{array}{l}\mathrm{EL} \\
(\%) \\
\end{array}$ & $\begin{array}{l}\mathrm{RA} \\
(\%) \\
\end{array}$ & $\begin{array}{c}\mathrm{T} \\
(\mathrm{hrs}) \\
\end{array}$ & $\begin{array}{l}\mathrm{EL} \\
(\%) \\
\end{array}$ \\
\hline L.S. & 1068 & 1268 & 25.0 & 37.5 & 1060 & 1197 & 14.8 & 27.0 & 55 & 14.4 \\
\hline Con. & 1038 & 1289 & 20.8 & 34.5 & 1005 & 1172 & 21.2 & 33.3 & 47 & 22.8 \\
\hline
\end{tabular}

* L.S.-- low segregation In 718; Con.-- conventional In 718.

ingots with very low contents of phosphrus $(<10 \mathrm{ppm})$. High temperature homogenization heat treatment tests show the easier tendency to reach homogenized structure, i.e. to eliminate $\mathrm{Nb}$ segregation to the lowest degree. However, $\mathrm{Nb}$ segregation of both ingots (low segregation and conventional) can be eliminated to meet industrial demand after 2 step high temperature long time homogenization treatment ( first step for Laves phase solution and the second step for homogenization of $\mathrm{Nb}$ ).

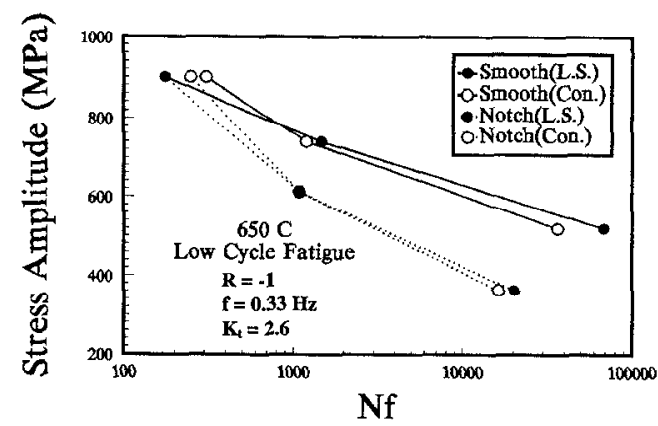

(a)

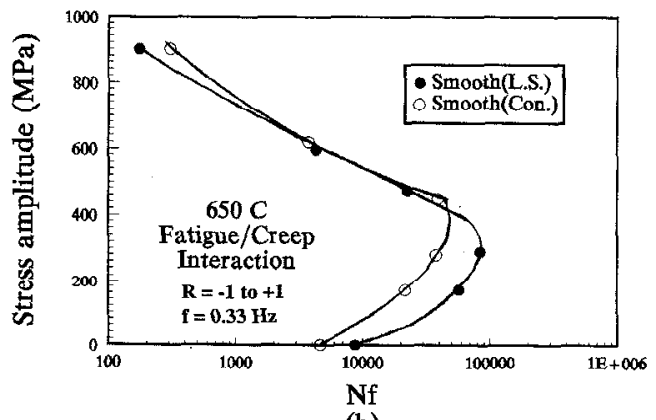

(b)

Figure 1 Stress controlled LCF(a) and fatigue/creep interaction(b) properties of low segregation and conventional IN718 disks.
Mechanical property test results including room temperature tensile, $650^{\circ} \mathrm{C}$ tensile and stress rupture, stress controlled LCF, stress controlled fatigue and creep interaction properties determination at $650^{\circ} \mathrm{C}$ for dieforging disks $(\sim 500 \mathrm{~mm}$ diameter $)$ have not revealed advantages of low segregation Inconel 718 in comparison with conventional Inconel 718 as shown in Table I and Figure. 1.

For further understanding the role of $\mathrm{P}$ in comparison with the role of $\mathrm{S}$ in Inconel 718, nine experimental heats were melted on the base of conventional Inconel 718 composition with the variation of $\mathrm{P}$ (from 10 to $130 \mathrm{ppm}$ ) and $\mathrm{S}$ (from 15 to $175 \mathrm{ppm}$ ) respectively.

\section{Meterials and Experimental Procedure}

Nine experimental heats of Inconel 718 with variation of $P$ and $\mathrm{S}$ were melted in $25 \mathrm{~kg}$ VIM furnace and poured in $15 \mathrm{~kg}$ ingots. Chemical composition and alloy designation are shown in Table II.

Nine ingots were conducted with 2 step homogenization treatment i.e., $1160^{\circ} \mathrm{C} / 24 \mathrm{hrs} \rightarrow 1180^{\circ} \mathrm{C} / 24 \mathrm{hrs} / \mathrm{A}$.C. All the ingots were forged down to $40 \mathrm{~mm}$ square bars and finally hot rolled to $18 \mathrm{~mm}$ round bars for tensile tests at room temperature and $650^{\circ} \mathrm{C}$, stress rupture and creep tests were conducted at $650^{\circ} \mathrm{C}, 686 \mathrm{MPa}$ and $725 \mathrm{MPa}$ respectively. Structural characterization and fractography analyses were carried out by means of optical, SEM and TEM microscopy.

\section{Results and Discussion}

The content of $P$ and $S$ in the range less than $130 \mathrm{ppm}$ and $175 \mathrm{ppm}$ respectively, both elements have almost no effect on tensile strengths (UTS and YS) and ductility (EL) at room temperature (see Fig.2 and 3). Phosphorus also has no effect on the strengths and ductilily at $650^{\circ} \mathrm{C}$ tensile test (see Fig.2b). Ilowever, sulfur has an obviously decreasing effect on $650^{\circ} \mathrm{C}$ tensile elongation as indicated in Fig. 3b. 
Table II. Chemical Composition of Test Alloys (wt $\%$ )

\begin{tabular}{|c|c|c|c|c|c|c|c|c|c|c|c|c|c|}
\hline Alloy & $\mathbf{C}$ & $\mathbf{M n}$ & $\mathbf{S i}$ & $\mathbf{S}$ & $\mathbf{P}$ & $\mathbf{N i}$ & $\mathbf{C r}$ & $\mathbf{M o}$ & $\mathbf{A l}$ & $\mathbf{T i}$ & $\mathbf{N b}$ & $\mathbf{B}$ & $\mathbf{F e}$ \\
\hline P1 & 0.02 & 0.02 & 0.05 & .001 & .0010 & 52.52 & 18.69 & 3.01 & 0.52 & 1.01 & 5.20 & .005 & bal. \\
\hline P2 & 0.03 & 0.02 & 0.05 & .002 & .0025 & 52.38 & 18.62 & 2.98 & 0.47 & 1.01 & 5.15 & .005 & bal. \\
\hline P3 & 0.03 & 0.02 & 0.06 & .003 & .0033 & 52.79 & 18.56 & 3.01 & 0.52 & 1.00 & 5.24 & .006 & bal. \\
\hline P4 & 0.02 & 0.02 & 0.05 & .003 & .0083 & 52.76 & 18.45 & 3.05 & 0.52 & 1.01 & 5.17 & .006 & bal. \\
\hline P5 & 0.02 & 0.02 & 0.05 & .003 & .0130 & 52.90 & 18.76 & 3.01 & 0.50 & 1.01 & 5.17 & .005 & bal. \\
\hline S1 & 0.04 & 0.02 & 0.05 & .0015 & .004 & 52.52 & 18.52 & 2.98 & 0.54 & 1.02 & 5.18 & .005 & bal. \\
\hline S2 & 0.04 & 0.02 & 0.11 & .0050 & .004 & 52.70 & 18.56 & 2.95 & 0.49 & 1.01 & 5.22 & .005 & bal. \\
\hline S3 & 0.02 & 0.02 & 0.06 & .0145 & .001 & 52.44 & 18.52 & 2.95 & 0.54 & 1.05 & 5.15 & .005 & bal. \\
\hline S4 & 0.02 & 0.02 & 0.06 & .0175 & .001 & 52.64 & 18.45 & 2.97 & 0.55 & 1.01 & 5.11 & .005 & bal. \\
\hline
\end{tabular}

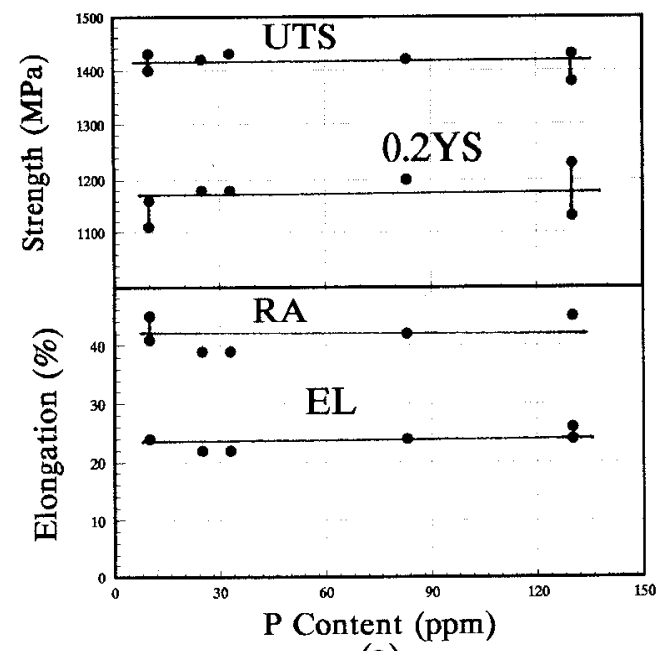

(a)

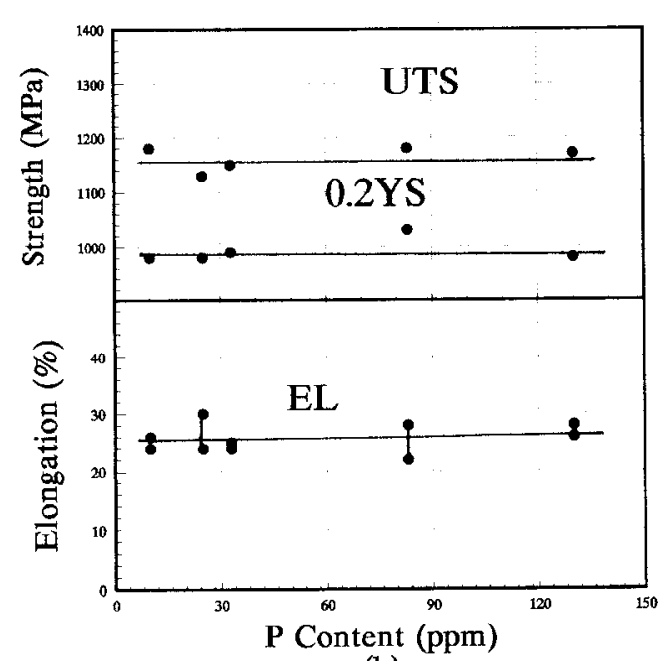

(b)

Figure 2 Effect of phosphorus on tensile properties at room temperature (a) and $650^{\circ} \mathrm{C}$ (b) of $\mathrm{N} 718$.

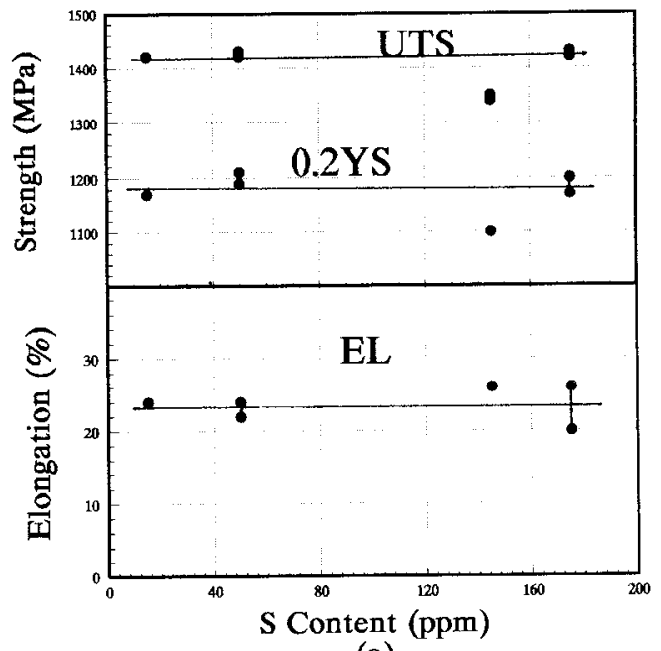

(a)

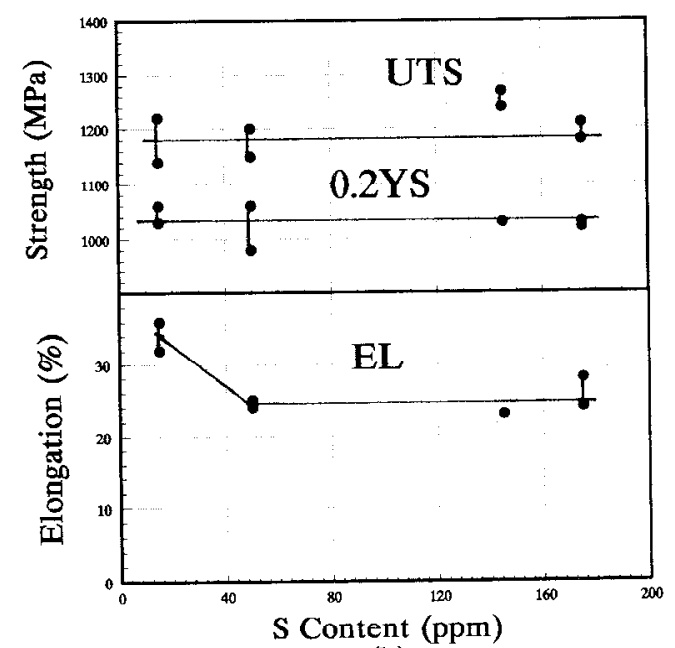

(b)

Figure 3 Effect of sulfur on tensile properties at room temperature (a) and $650^{\circ} \mathrm{C}$ (b) of IN718. 


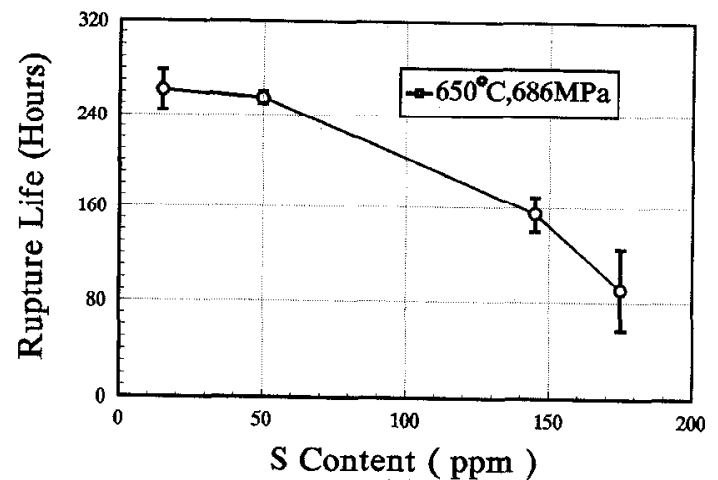

(a)

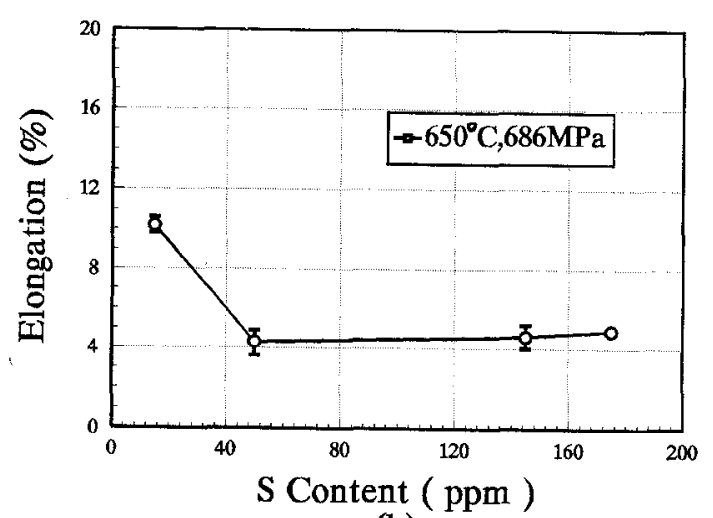

(b)

Figure 4 Effect of sulfur on $650^{\circ} \mathrm{C}, 686 \mathrm{MPa}$ stress rupture life (a) and ductility (b) of IN718.

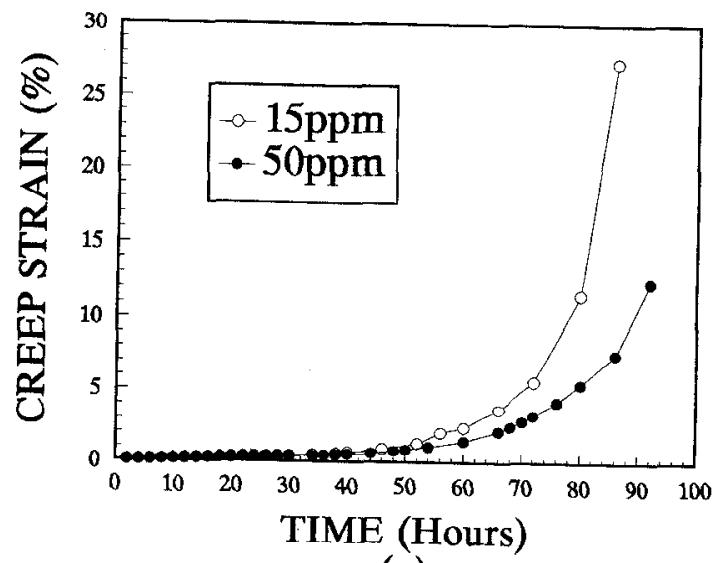

(a)

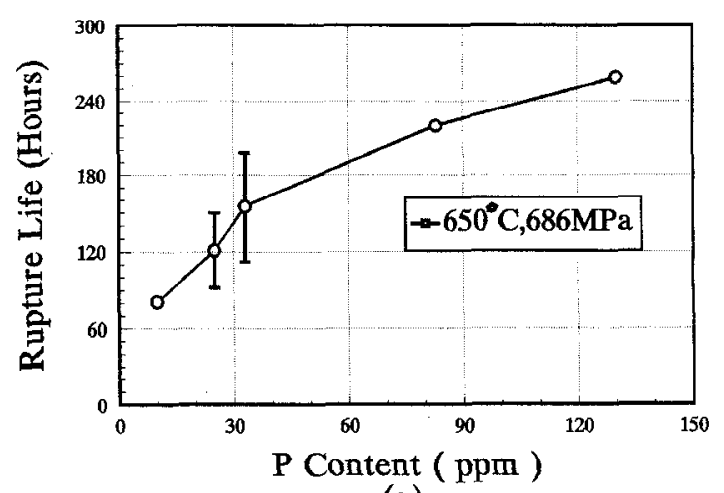

(a)

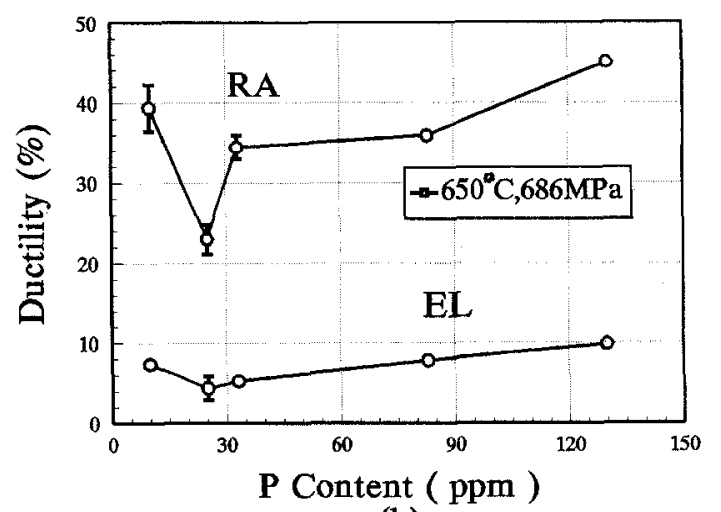

(b)

Figure 5 Effect of phosphorus on $650^{\circ} \mathrm{C}, 686 \mathrm{MPa}$ stress rupture life (a) and ductility (b) of IN718.

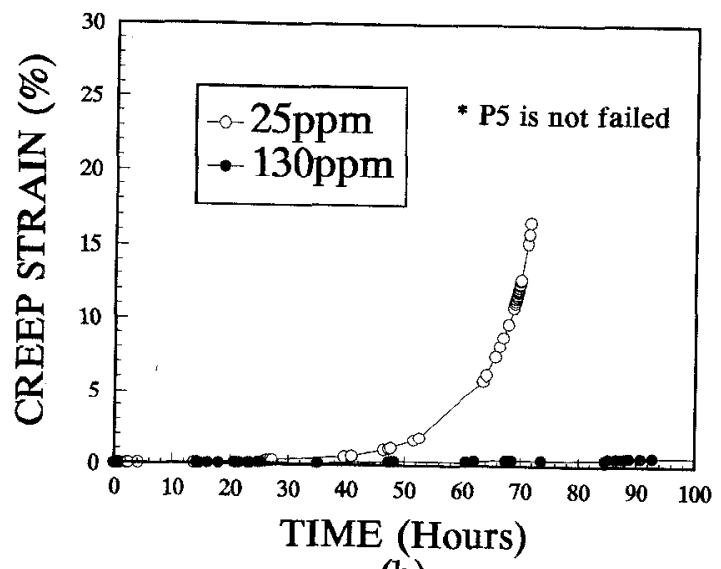

(b)

Figure 6 Effect of sulfur (a) and phosphorus (b) on $650^{\circ} \mathrm{C}, 725 \mathrm{MPa}$ creep curves of IN718. 
Sulfur has a remarkable detrimental effect on stress rupture life and especially ductility loss even at a small amount of sulfur content in Inconel 718 as shown in Fig.4. However. phosphorus is in toral difference to sulfur effect, P can increase stress rupture life and ductilities (see Fig.5). It implies that $\mathrm{P}$ has certain strengthening and ductility improvement effects. Special attention should be paid, that Alloy 718 with low content of P ( $20 \mathrm{ppm})$ is susceptible to the lowest ductilities at $650^{\circ} \mathrm{C}$ stress rupture test (Fig. 5b shows the "lowest valley" of stress rupture ductility curve), which shows consistence with the experimental results of Cao and Kennedy ${ }^{15}$.

Creep test results at $650^{\circ} \mathrm{C}$ show that $\mathrm{S}$ and $\mathrm{P}$ have no influence on secondary creep rates, However, phosphorus can prolong secondary creep stage tremendously (Fig.6b). In results of that Alloy 718 with higher content of phosphorus characterizes with longer creep failure life.
Microstructure observation on grain structure, $\delta$-phase at grain boundaries, $\gamma^{\prime \prime}$ and $\gamma^{\prime}$ precipitates in the grains can not reveal the effect of $\mathrm{P}$ and $\mathrm{S}$ on the grain size and morphology and amount of precipitates (see Fig. 7 and 8).

Metalographic observation on the longitudinal sections of stress rupture failure specimens shows typical grain boundary cracks in all specimens with different contents of $S$ and $P$ respectively. These results show all the failures at $650^{\circ} \mathrm{C}$ stress rupture tests characterize with intergranular fracture. Alloy 718 with low content of S (Alloy S1 with 15 ppm sulfur) clearly shows deformed and prolonged grain structure (see Fig.9a) because of the longer stress rupture life and higher ductility of Alloy $\mathrm{S} 1$ in comparison with Alloy S4 (175ppm sulfur) as shown in Fig.9b. However, Alloy P5 with highest content of P(130ppm)

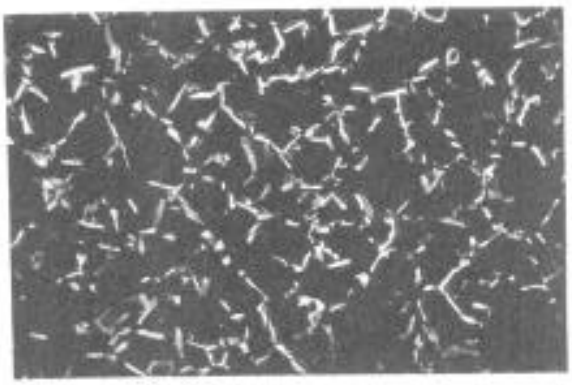

(a)

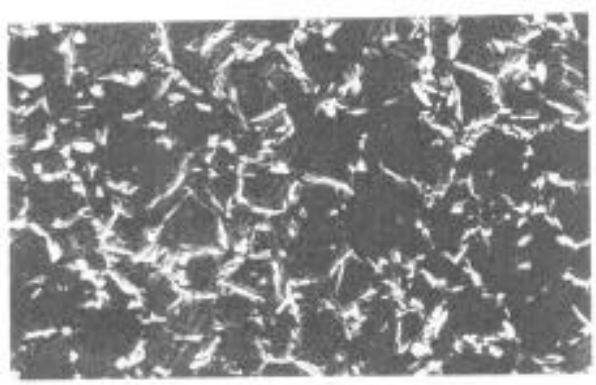

(c)

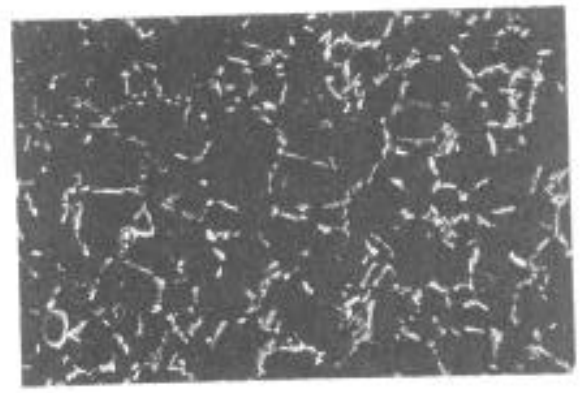

(b)

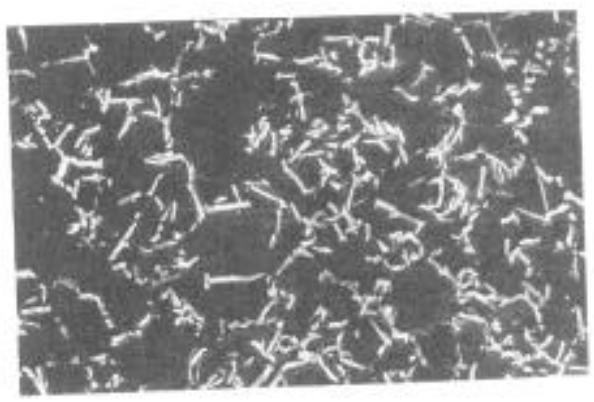

(d)

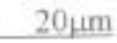

Figure 7 Effect of sulfur and phosphorus on grain structure and 8-phase in IN718.

a-SI $(15 p p m S) ; \quad$ b-S4(175ppm S); c-P2(25ppm P); d-P5(130ppm P) 


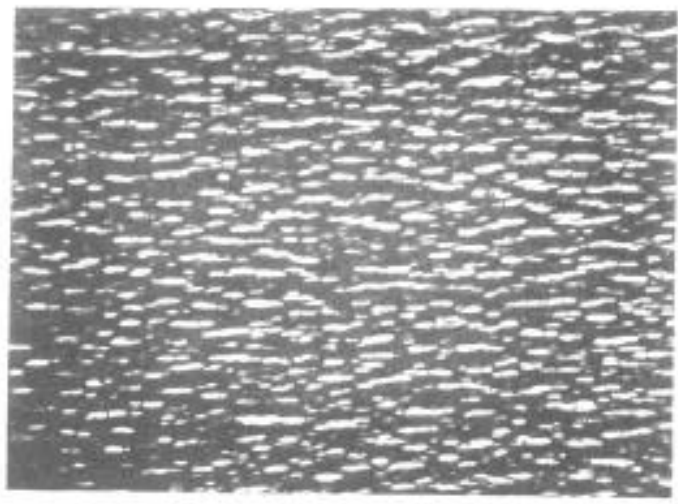

(a)

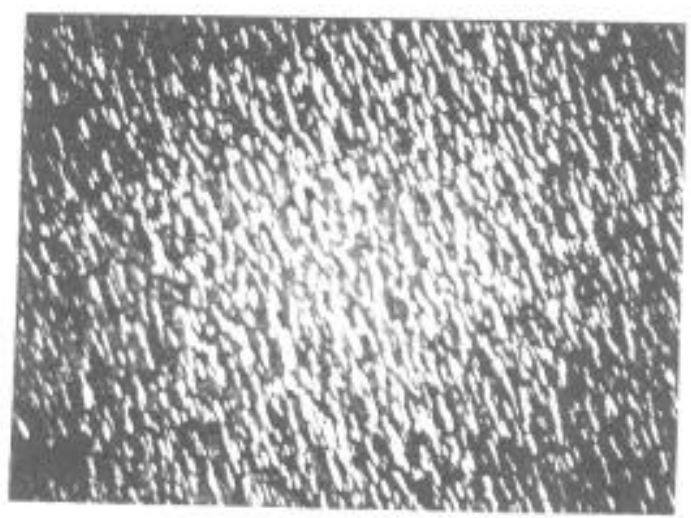

(b)

$200 \mathrm{~nm}$

Figure 8 Effect of sulfur and phosphorus on $\gamma^{n}$ and $\gamma^{\prime}$ precipitates in IN718. a -P5(130ppm P, 30ppm S);b - S4(10 ppm P, 175 ppm S).

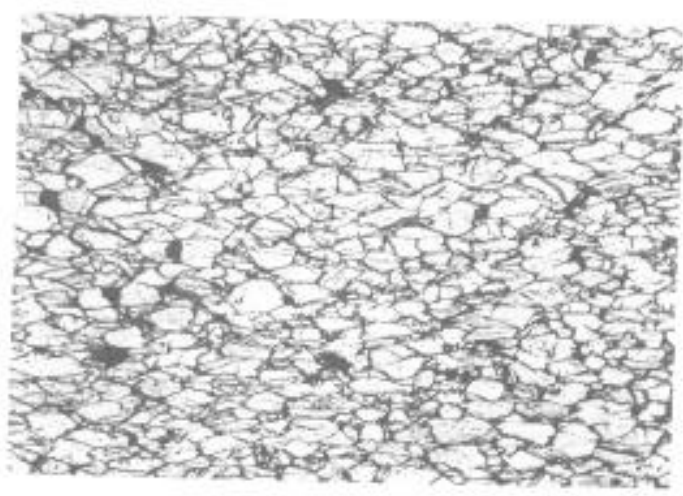

(a)

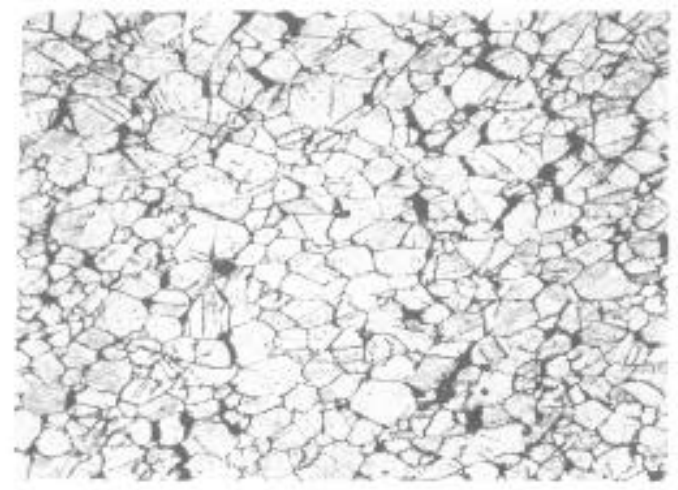

(c)

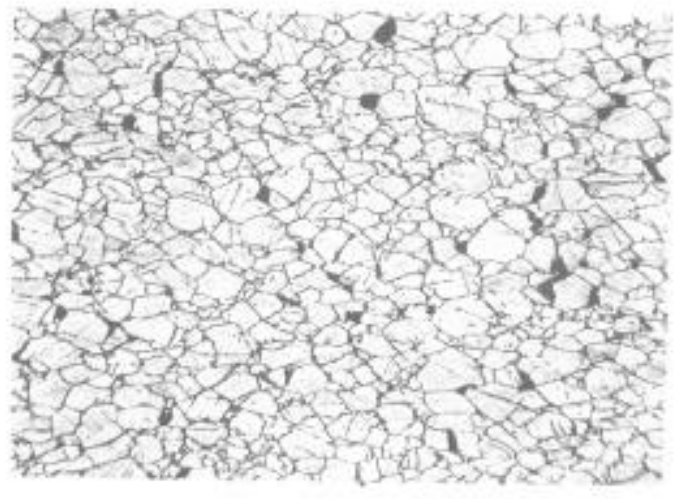

(b)

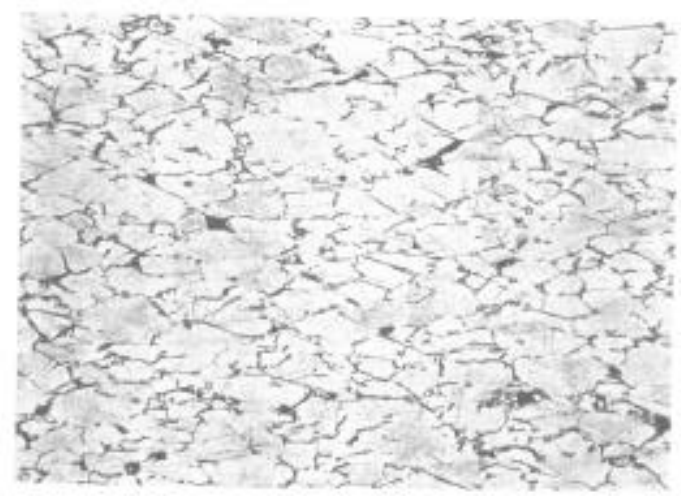

(d)

$50 \mu \mathrm{m}$

Figure 9 Effect of sulfur and phosphorus on fracture manner at longitudinal direction of $650^{\circ} \mathrm{C}$ stress rupture failed specimens.

a - S1 (15ppm S); b-S4(175ppm S); c-P2(25ppm P); d- P5(130ppm P) 


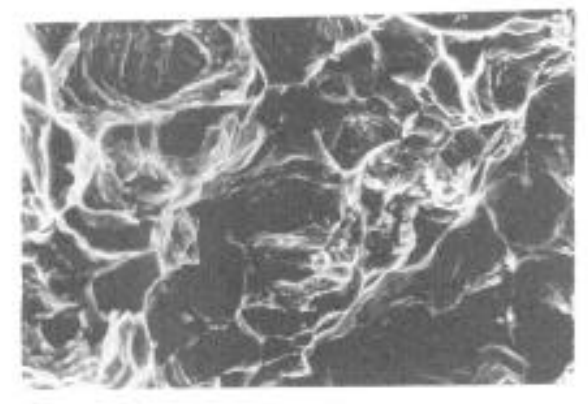

(a)

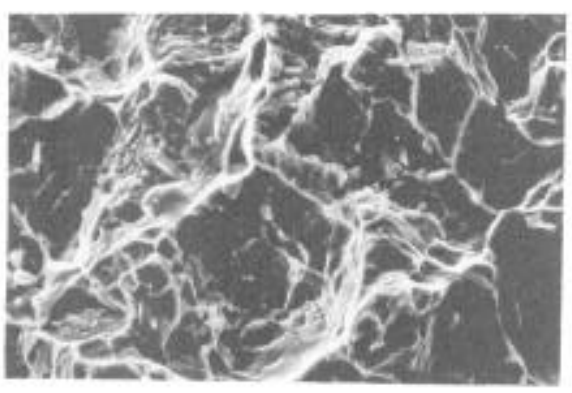

(c)

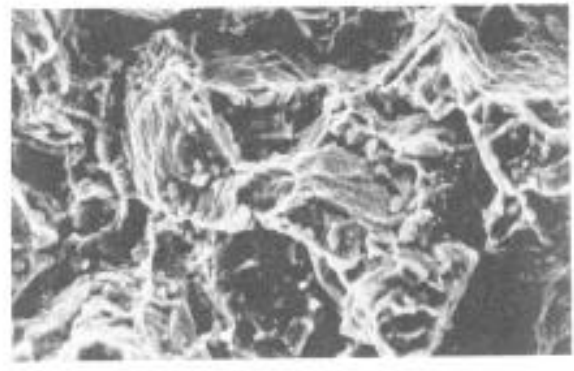

(b)

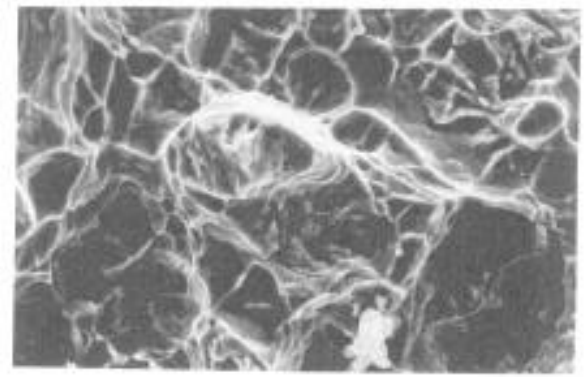

(d)

Figure 10 Fractography observation on the effect of sulfur and phosphorus in IN718. a-SI(15ppm S); b-S4(175ppm S); c-P2(25ppm P); d-P5(130ppm P)

among our experimental heats characterizes typical deformed and prolonged grain structure, which is in total reverse in comparison with the S effect (see Fig.9d) SEM fractograpy observation direct on the fracture surfaces after $650^{\circ} \mathrm{C}$ stress rupture tests shows that Alloy SI with the lowest content of $\mathrm{S}(15 \mathrm{ppm})$ characterizes more ductile intergranular fracture mode (see Fig. 10a and b). However. phosphorus promotes the fracture to be more ductile as shown in Fig. $10 \mathrm{c}$ and $10 \mathrm{~d}$.

From above mentioned comprehensive experimental results it can be concluded that the effects of $\mathrm{P}$ and $\mathrm{S}$ on mechanical properties in IN 718 are as follows:

1. Phosphorus and sulfur both have almost no influence on strengths and ductilities at room temperature tensile test.

2. Phosphorus also has no effects on the yield and ultimate strengths and elongation at $650^{\circ} \mathrm{C}$ tensile test. However, sulfur has an obviously decreasing effect on $650^{\circ} \mathrm{C}$ tensile elongation but no effect on yield and ultimate strengths.
3. Sulfur has a remarkable detrimental effect on stress rupture (creep) life and especially on ductility loss (tertiary creep) at $650^{\circ} \mathrm{C}$. However, phosphorus is in total difference to sulfur effect. Phosphorus can increase stress rupture life and ductility, as well as prolong secondary creep and develop tertiary creep both.

Microstructure and fractography observation reveals that phosphorus and sulfur have only the effect on these mechanical properties characterized with intergranular fracture, especially for high temperature stress rupture or creep failures, however the effects of $\mathrm{P}$ and $\mathrm{S}$ are in totally different manner.

Special attention should be paid, that $\mathrm{P}$ has certain high temperature strengenthing and ductility improvement effects. Only a few experimental results in the recent years show that phosphorus can be benifical for high temperature stress rupture, creep and creep-fatigue properties in $\mathrm{IN} 718^{(5)}$, Ni-Cr-Fe ${ }^{(6)}$ and $304 \mathrm{~L}^{(7)}$ austenitic alloys as we have in this investigation. To the best of 
today's knowledge, the reason of beneficial effect of $P$ in these alloys is still not clear yet.

Phosphorus and sulfur seriously aggravate dendritic segregation during solidification and both are concentrated at grain boundaries after heat treatment of wrought IN718. These effects have been already experimentally determined $^{(2-5,8)}$. Theoretical explanation is tried to make that based on the first principle interatomic potential study suggested by Wang et al. ${ }^{(9)}$ to calculate the doping effects on the $\mathrm{Ni} \sum 11[110]$ tilt grain boundary by using Discrete Variational $X_{\alpha}$ Method (DVM). However, their results ${ }^{(10)}$ indicate that both $\mathrm{P}$ and $\mathrm{S}$ elevate the binding energy of atom clusters at grain boundaries and the equilibrium lattice constant (ELC) at grain boundaries in nickel. The ELC of pure nickel grain boundary is $3.6000 \AA$ while the Pdoping's and the S-doping's grain boundaries are $3.8555 \AA$ and $3.8823 \AA$ respectively. Therefore, the segregation of $P$ and $S$ at grain boundaries leads to the grain boundary embrittlement in nickel. However, Inconel 718 is a very complicated multi-component alloy system. An hypothesis is trying to take in consideration, that phosphorus may interact with the other elements and they may co-exist at the grain-boundaries to decrease grain boundary binding energy and to increase grain boundary cohesive force. In results of these, phosphorus may effectively strengthen grain boundary and to retard grain boundary crack til to failure at high temperature tests. A further research program is going to enlighten the $P$ effect in IN718.

\section{Conclusions}

1. Phosphorus and sulfur both have almost no influence on strenghts and ductilities at room temperature tensile test. Phosphorus also has no effect on the yield and ultimate strengths and elongation at $650^{\circ} \mathrm{C}$ tensile test. However, sulfur has an obviously decreasing effect on $650^{\circ} \mathrm{C}$ tensile elongation but no effect on yield and ultimate strengths.

2. Sulfur has a remarkable detrimental effect on stress nupture life and especially on ductility loss at $650^{\circ} \mathrm{C}$. However, phosphorus is in total difference to sulfur effect, generally can increase stress rupture (creep) life and ductility.

3. Microstructure observation on grain structure, $\delta$-phase and strengthening phase $\gamma^{\prime \prime}$ and $\gamma^{\prime} \quad$ can not reveal the effect of $P$ and $S$ on the morphology and amount of precipitates Fractography analyses show different patterns of failed stress rupture specimens with the variation of $P$ and $S$ contents. Experimental results lead us to consider the segregation behaviors of $P$ and $S$ at grain boundaries, however the effect of $P$ and $S$ should be different.

4. Sulfur is regarded as a detrimental impurity in Inconel 718 and it should be controlled at the lowest level in alloy production.
5. From the view point of serious segregation problem in Inconel 718 the production of low segregation Inconel 718 , suggested to control $P$ content at very low level $(<10 \mathrm{ppm})$, was successfully conducted. Industrial results have not shown any benefits for mechanical properties. However, laboratory experimental results show that very low level phosphorus leads stress rupture (creep) life loss.

6. Phosphorus seems to be benifical for stress rupture life and ductility improvement, however its mechanism is still not clear yet.

\section{$\underline{\text { References }}$}

(1) A. Mitchell, "Progress in Understanding Clean Metal Production for IN 718", Superalloys 718, 625, 706 and Various Derivatives Ed. E.A. Loria, TMS(1994) P.109

(2) Y. Zhu et al., "Effect of P, S, B and Si on the Solidification on INCONEL 718 Alloy", Superalloys 718. 625, 706 and Various Derivatives Ed. E.A. Loria, TMS(1994) P.89

(3) C. Chen, R.G. Thompson and D.W. Davis, "A Study of Effects of Phosphorus, Sulfur, Boron and Carbon on Laves and Carbide Formation in Alloy 718", Superalloys 718 , 625, 706 and Various Derivatives Ed. E.A. Loria, TMS(1991) P.81

(4) Y. Zhu et al., "A New Way to Improve the Superalloys", Superalloys 1992 Eds. S.D. Antolovich et al., TMS(1992) P.145

(5) W.D. Cao and R.L. Kennedy, "The effect of Phosphorus on Mechanical Properties of Alloy 718", Superalloys 718, 625, 706 and Various Derivatives Ed. E.A. Loria, TMS(1994)P.463

(6) G.S. Was, J.K. Sung and T.M. Angeliu, "Effects of Grain Boundary Chemistry on the Intergranular Cracking Behaviors of $\mathrm{Ni}-16 \mathrm{Cr}-9 \mathrm{Fe}$ in High-Temperature Water", Met. Trans. 23A(1992) P.3343

(7) Y.C. Yoon et al, "Effect of Phosphorus on the CreepFatigue Interaction in AISI 304L Stainless Steel, J. of the Korean Inst. of Met. \& Mater. 30(1992) P. 1401

(8) R.G. Thompson, Personal Communication, Univ. of Alabama at Birmingham (1995)

(9) Wang Chongyu et al., "A First Principle Interatomic Potential and Application to Grain Boundary in Nickel", Phys. Letter A197 (1995) P.447

(10) Wang Chongyu, Wang Ligen and Wang Fuhe, "Binding Energy and Doping Effect of Grain Boundary on the First Principle Calculations for Transition Metal", Inter. Conf. of IUMRS in Asia (1993) P.109 